\title{
$\begin{array}{ll}\text { Research Square } & \text { Preprints are preliminary reports that have not undergone peer review. }\end{array}$ or referenced by the media as validated information. \\ Early registration for antenatal care was associated with improved birth outcomes in a low-income community in Harare
}

Tonderayi Mathew Matsungo ( $\boldsymbol{\nabla}$ tmatsungo@gmail.com )

University of Zimbabwe https://orcid.org/0000-0001-9836-7780

\section{Shingai Mudzuri}

University of Zimbabwe

Prosper Chopera

University of Zimbabwe

Research article

Keywords: ANC, Prenatal care, Pregnant mothers, low birth weight, stunting, Zimbabwe

Posted Date: April 27th, 2020

DOI: https://doi.org/10.21203/rs.3.rs-21962/v1

License: (c) (1) This work is licensed under a Creative Commons Attribution 4.0 International License.

Read Full License 


\title{
TITLE PAGE
}

Early registration for antenatal care was associated with improved birth outcomes in a low-income community in Harare

\author{
Matsungo $\mathrm{TM}^{1 *}$, Mudzuri $\mathrm{S}^{1}$, and Chopera $\mathrm{P}^{1}$ \\ ${ }^{1}$ Institute of Food, Nutrition and Family Sciences, Faculty of Science, University of Zimbabwe, P O \\ Box MP 167, Mt Pleasant, Harare, Zimbabwe
}

*Correspondence: Dr TM Matsungo. Email: tmatsungo@gmail.com 


\begin{abstract}
Background: The World Health Organization (WHO) recommends early registration, regular and consistent attendance of antenatal care (ANC) sessions for all pregnant women. Specifically, if ANC services promote evidence-based practices this improves pregnancy outcomes and reduce maternal mortality. Yet there are worrying gaps in knowledge of antenatal care services in Zimbabwe. Objectives: To determine the relationship between early registration and frequency of ANC visits on birth weight, birth length, head circumference, Apgar score, birth complications, delivery mode, preterm birth and duration of labour among women aged 15-49 from Hatcliffe Polyclinic, Harare. Methods: This was a health facility based retrospective cross-sectional study. An interviewer administered questionnaire was used to collect data. Data was entered and analysed using SPSS version 20. Descriptive statistics, and associations between dependent and independent variables were determined using Pearson's Chi-square and Fisher's exact test. Ethical approval was granted from the Medical Research Council of Zimbabwe (MRCZ/B/1438). Results: A total of 75 mother child pairs were interviewed. Most (77.3\%) had more than four ANC visits. Only 36\% registered early (during first trimester). Most of the children had normal birth weight $\geq 2500 \mathrm{~g}$ (80.3\%), birth length $\geq 47 \mathrm{~cm},(76 \%)$, head circumference $\geq 33 \mathrm{~cm}(80 \%)$, and Apgar score $\geq 7(96 \%)$. A positive association was observed between number of ANC visits and birth weight [Odds ratio (OR) 7.6; 95\% Confidence Interval (CI) 1.6, 36.4 (p=0.013)], birth length [OR 6.1; 95\%CI 1.8, 20.1 $(\mathrm{p}=0.010)]$, and head circumference [OR 4.3; 95\% CI 1.3, $14.8(\mathrm{p}=0.013)]$. Positive associations were also observed between timing of registration and birth weight [OR 1.2; 95\% 1.05, $1.36(\mathrm{p}=0.045)$ ], birth length [OR 0.16; 95\% CI 0.03, $0.76(\mathrm{p}=0.012)$ ]. Conclusions: In this study increased frequency and early registration for ANC visits had a positive relationship with birth weight, birth length and head circumference. These findings show the need for improving the uptake of ANC services, early registration for ANC in the first trimester and adoption of community wide strategies to ensure that pregnant women attend all recommended visits for improved birth outcomes in this and related settings.
\end{abstract}

Keywords: ANC, Prenatal care, Pregnant mothers, low birth weight, stunting, Zimbabwe 


\section{Background}

Antenatal care (ANC) is one of the core interventions for improving maternal and birth outcomes [1, 2]. According to WHO definition, the components of ANC include: risk identification; prevention and management of pregnancy-related or concurrent diseases; and health education and health promotion in order to ensure the best health conditions for both mother and baby during pregnancy [2]. The overall aim of ANC services is to deliver evidencebased interventions delivered at four critical times during pregnancy [3, 4].

Although, in low- and middle-income countries (LMICs), like Zimbabwe the utilisation of ANC services surged in 2002 due to the introduction of focused ANC, more work needs to be done to address ANC utilisation and quality [2]. This is important considering that the prenatal period is an important component of the 1000 days window of opportunity. The lancet series of 2013 revealed the need for the scaling up of nutrition specific and sensitive interventions including ANC so as to prevent maternal mortality and improve birth outcomes [5, 6]. Early registration and regular access by pregnant mothers to quality ANC services potential to reduce maternal mortality and morbidity in LMIC settings [7]. Therefore, failure by health providers to achieve this often results in rising deaths of mothers during delivery and some poor pregnancy outcomes; preterm birth and low birth weight (LBW) [2, 8]. Nearly 15 million infants worldwide are born preterm each year [9] and over 20 million children worldwide were born with LBW[10]. In 2018 the average proportion of babies born with LBW in Zimbabwe was at 20 percent [11].

ANC services has long been endorsed as a major means to identify and to reduce the risks of pre-term, low-birth weight, and other adverse pregnancy conditions and birth outcomes [2, 12]. However, there is limited evidence on the effectiveness of ANC services in LMICs to inform programme and policy decisions [13]. Zimbabwe adopted the 2002 WHO Focused ANC (FANC) recommendations of at least four ANC visits during a woman's pregnancy, including urine testing for bacteriuria and proteinuria, blood pressure measurement, blood grouping and Rhesus factor, blood testing to detect syphilis, HIV and anaemia and weight and height measurements [14].

However, the 2015 demographic health survey results showed that only $39 \%$ had registered or attended ANC session in their first trimester of pregnancy ( $<4$ months), while $76 \%$ reported to have had achieved the recommended 4 or more ANC visits [14]. In addition, among women aged 15-49 years who gave birth in period 2010-2015, 93\% had received ANC from a skilled 
health worker during pregnancy [14]. This shows the need to expand the coverage and utilisation of ANC services in Zimbabwe. Furthermore, we still have worrying gaps in knowledge of antenatal care services in Zimbabwe. Consequently, this study investigated the relationship between frequency and timing of ANC visits and birth outcomes among women aged 15-49 years in Hatcliffe suburb, Harare, Zimbabwe.

\section{Methods}

\section{Study design and setting}

A facility based retrospective cross-sectional study was conducted at Hatcliffe Polyclinic in Harare, Zimbabwe to establish the relationship between ANC visits and birth outcomes. Hatcliffe suburb is a peri urban low-income community in North East of the capital city Harare. The area has the following geographical coordinates $17^{\circ} 41^{\prime} 18^{\prime \prime}$ South, $31^{\circ} 6^{\prime} 35^{\prime \prime}$ East and enjoys subtropical highland climate or temperate oceanic climate with dry winters. Based on the results of the 2012 national census Hatcliffe has an estimated 11658 households and a population exceeding 45000 people [15].

\section{Sampling and sample size determination}

The sample size consisted of women $(n=75)$ with children below 2 years. This is reflective of the Zimbabwe situation where there is low uptake of postnatal care services (PNC), as mothers tend to disappear from the health system radar soon after giving birth. Convenient sampling method was used to select mothers attending the ANC sessions at the clinic. Mothers always bring the child health cards for ANC visits and this ensured collection of correct information on birth weight, birth length and Apgar score.

\section{Data collection and tools}

An interviewer administered questionnaire adapted from the multiple indicator cluster survey (MICS) tool was used to collect data on [16]on the number and timing of ANC visits, type of ANC service provider, content of ANC which include blood pressure measurement, blood and urine samples taken and iron and folate supplementation. Birth outcomes (the child's length, weight, Apgar score and head circumference) were recorded from the child health card.

\section{Definitions and cut-offs}

Early registration for ANC was defined in this study as registering within the first 12 weeks of pregnancy and registration after 12 weeks of pregnancy was regarded as late registration based 
on WHO guidance [2]. The definitions of normal birth weight $(\geq 2500 \mathrm{~g})$, length $(\geq 46.9 \mathrm{~cm})$ and head circumference $(\geq 32.9 \mathrm{~cm})$ were based on standard recommended cut-offs [17]. While, birth complications was defined as presence of any of the following, birth by Caesarean section, longer duration of labour (> 7 hours) and preterm birth (delivery before 37 completed weeks of gestation based on the last self-reported menstrual period) [7]. Adequate ANC visits was based on WHO guidelines, where four or more visits are considered as adequate [2].

\section{Data analysis}

Data collected was entered and analysed using SPSS v 25 (IBM Inc). Normality of data was assessed using the Shapiro-Wilk test and visualisations via Q-Q plots. Continuous data was presented as mean \pm standard deviation $(\mathrm{SD})$ while categorical data was presented as frequencies and percentages. Pearson's Chi-square test was used to compare categorical data, when cell counts were less than 5, Fisher's exact test was used instead. Level of significance was set at $\mathrm{P}<0.05$.

\section{Results}

Sociodemographic characteristics of participants

A total of 75 mothers of children aged 0-24 months consented to participate in this study. Table 1 presents a summary of the sociodemographic variables of the participants of the study. The youngest mother interviewed was 18 years old and the oldest was 45 years. Most of the women were married (84\%), and most had achieved at least secondary level of education $(70 \%)$. We observed that $93.2 \%$ of the times nurses had attended to the mothers during ANC visits and a smaller number $(6.8 \%)$ were attended to by a doctor. Similarly, regarding delivery assistance a high proportion $(74.7 \%$ ) had been attended to by a midwife and $21.3 \%$ were assisted by a doctor. Most of the women had the basic ANC assessments; blood pressure assessed (74\%), urine sample collected to confirm the pregnancy (74\%), iron and folate supplementation provided or prescribed (76\%). Almost all infants of interviewed mothers had been delivered at a health facility $(94 \%)$. The mean \pm SD duration of labour was $7.6 \pm 4.77$ hours and the prevalence of normal delivery was $89.3 \%$. The mean \pm SD birth weight was $2804 \pm 3.96 \mathrm{~g}$, birth length was $48.44 \pm 3.92 \mathrm{~cm}$, head circumference was $33.91 \pm 1.91 \mathrm{~cm}$. 
Table 1: Socio-demographics of study participants

\begin{tabular}{|c|c|c|c|}
\hline \multicolumn{2}{|l|}{ Variable } & \multirow{2}{*}{$\begin{array}{c}\text { Frequency (n) } \\
5\end{array}$} & \multirow{2}{*}{$\begin{array}{c}\text { Percentage }(\%) \\
6.7\end{array}$} \\
\hline Mother`s age (years): & $15-19$ & & \\
\hline & $20-34$ & 53 & 70.6 \\
\hline & $35-45$ & 17 & 22.7 \\
\hline \multirow[t]{3}{*}{ Marital status: } & Single & 2 & 2.7 \\
\hline & Married & 63 & 84 \\
\hline & Divorced/ Separated & 10 & 13.4 \\
\hline \multirow[t]{4}{*}{ Education level: } & No formal education & 2 & 2.7 \\
\hline & Primary & 5 & 6.7 \\
\hline & Secondary & 53 & 70.7 \\
\hline & Tertiary & 15 & 20 \\
\hline \multirow[t]{2}{*}{ Sex of child: } & Boys & 36 & 48 \\
\hline & Girls & 39 & 52 \\
\hline \multirow[t]{3}{*}{ Child`s age in months: } & $0-6$ & 29 & 38.7 \\
\hline & $7-12$ & 21 & 28 \\
\hline & $13-24$ & 25 & 33.3 \\
\hline \multirow[t]{2}{*}{ Child`s birth order: } & $1^{\text {st }}$ born & 21 & 28 \\
\hline & $2^{\text {nd }}$ to $5^{\text {th }}$ born & 54 & 72 \\
\hline \multirow[t]{2}{*}{ ANC staff consulted: } & Doctor & 5 & 6.8 \\
\hline & Nurse & 68 & 93.2 \\
\hline \multicolumn{2}{|c|}{ Blood pressure measured } & 74 & 98.6 \\
\hline \multicolumn{2}{|l|}{ Urine sample assessed } & 74 & 98.6 \\
\hline \multicolumn{2}{|c|}{ Iron and folate supplementation } & 57 & 76 \\
\hline \multicolumn{2}{|l|}{ Tetanus injection } & 67 & 89.3 \\
\hline \multirow[t]{3}{*}{ Birth delivery by: } & Doctor & 16 & 21.3 \\
\hline & Nurse & 56 & 74.7 \\
\hline & Relative or friend & 3 & 4 \\
\hline \multirow[t]{2}{*}{ Place of delivery: } & Home & 4 & 5.3 \\
\hline & Health facility & 71 & 94.7 \\
\hline \multirow[t]{2}{*}{ Mode of delivery: } & Normal & 67 & 89.3 \\
\hline & C-Section & 8 & 10.0 \\
\hline \multicolumn{3}{|c|}{ Duration of labour (hrs), mean \pm SD $(n=67)$} & $7.6 \pm 4.8$ \\
\hline \multicolumn{3}{|c|}{ Birth weight $(\mathrm{g})$, mean $\pm \mathrm{SD}(\mathrm{n}=75)$} & $2804 \pm 396$ \\
\hline \multicolumn{3}{|c|}{ Birth length $(\mathrm{cm})$, mean $\pm \mathrm{SD}(\mathrm{n}=75)$} & $48.4 \pm 3.9$ \\
\hline \multicolumn{3}{|c|}{ Head circumference $(\mathrm{cm})$, mean $\pm \mathrm{SD}(\mathrm{n}=75)$} & $33.9 \pm 1.9$ \\
\hline
\end{tabular}


An association was observed between number of ANC visits and birth weight [Odds ratio (OR) 7.6; 95\% Confidence Interval (CI) 1.6, 36.4 (p=0.013)], birth length [OR 6.1; 95\%CI 1.8, $20.1(\mathrm{p}=0.010)$ ], and head circumference [OR 4.3; 95\% CI 1.3, $14.8(\mathrm{p}=0.013)]$. There was no relationship between the number of ANC visits and Apgar score $(\mathrm{p}=0.127)$ (Table 2)

Table 2: Relationship between number of ANC visits on birth weight, length, head circumference and Apgar score

\begin{tabular}{lccccc}
\hline Variable & \multicolumn{5}{c}{ ANC visits } \\
& Total & $\begin{array}{c}\text { less than } \mathbf{4} \\
\mathrm{n}=17\end{array}$ & $\mathbf{4}$ or more \\
& $\mathrm{n}=75$ & $\mathbf{n}(\boldsymbol{\%})$ & $\mathbf{n}(\boldsymbol{\%})$ & P-value & OR (95\% CI) \\
\hline Birth weight $(<2.5 \mathrm{~kg})$ & $8(10.6)$ & $5(42.1)$ & $3(5.4)$ & & \\
Normal & $67(80.3)$ & $12(57.9)$ & $55(94.6)$ & $0.013^{*}$ & $7.6(1.6,36.4)$ \\
Birth length $(<47 \mathrm{~cm})$ & $18(24.0)$ & $9(57.9)$ & $8(14.3)$ & & \\
Normal & $57(76.0)$ & $8(42.1)$ & $49(85.7)$ & $0.01^{*}$ & $6.1(1.8,20.1)$ \\
Head circumference $(<33 \mathrm{~cm})$ & $15(20)$ & $7(42.1)$ & $8(12.5)$ & & \\
Normal & $60(80)$ & $10(18.3)$ & $50(81.7)$ & $0.013^{*}$ & $4.3(1.3,14.8)$ \\
Apgar Score $(<7$ points $)$ & $3(4)$ & $2(10.5)$ & $1(1.8)$ & & \\
$\quad$ Normal & $72(96)$ & $15(89.5)$ & $57(98.2)$ & 0.127 & $7.6(0.6,89.6)$ \\
\hline
\end{tabular}

${ }^{1}$ Chi-square test of association was used to obtain $\mathrm{P}$ values and Odds ratios except where cell count is $<5$ Fisher's exact test was used. *P value significant at $\mathrm{P}<0.05$

Early compared to late registration for ANC and birth outcomes

Table 3 presents a summary of the relationship between early compared to late registration for ANC by birth outcomes. The results revealed that there was a significant association between timing of registration and birth weight [OR 1.2; 95\% 1.05, $1.36(\mathrm{p}=0.045)]$, birth length [OR $0.16 ; 95 \%$ CI $0.03,0.76(\mathrm{p}=0.012)]$. While, in the contrary, we observed no significant association between early registration of ANC and infant Apgar score $(p=0.293)$. 
Table 3: Relationship of early vs. late registration for ANC with the birth outcomes

\begin{tabular}{|c|c|c|c|c|c|}
\hline \multirow[b]{2}{*}{ Variable } & \multirow[b]{2}{*}{ 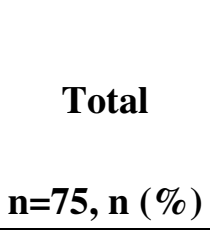 } & \multicolumn{2}{|c|}{ Registration for ANC } & \multirow[b]{2}{*}{$\begin{array}{c}{ }^{1} P \text { - } \\
\text { value }\end{array}$} & \multirow[b]{2}{*}{$\begin{array}{c}\text { OR } \\
(95 \% \mathrm{CI})\end{array}$} \\
\hline & & $\begin{array}{l}\begin{array}{l}\text { Before } 1^{\text {st }} \\
\text { trimester } \\
\mathbf{n}=27(36)\end{array} \\
\end{array}$ & $\begin{array}{c}\begin{array}{c}\text { After } 1^{\text {st }} \\
\text { trimester } \\
\mathrm{n}=48(64)\end{array} \\
\end{array}$ & & \\
\hline Birth weight $(<2.5 \mathrm{~kg})$ & $8(10.6)$ & 0 & 8 & \multirow{2}{*}{$0.045^{*}$} & \multirow{2}{*}{$1.2(1.05,1.36)$} \\
\hline Normal & $67(80.3)$ & 27 & 40 & & \\
\hline Birth length $(<47 \mathrm{~cm})$ & $18(24.0)$ & 2 & 16 & \multirow{2}{*}{$0.012 *$} & \multirow{2}{*}{$0.16(0.03,0.76)$} \\
\hline Normal & $57(76.0)$ & 25 & 32 & & \\
\hline $\begin{array}{l}\text { Head circumference } \\
(<33 \mathrm{~cm})\end{array}$ & $15(20)$ & 2 & 13 & \multirow{2}{*}{0.070} & \multirow{2}{*}{$0.2(0.04,1.04)$} \\
\hline Normal & $60(80)$ & 25 & 35 & & \\
\hline Apgar Score (<7 points) & $3(4)$ & 2 & 1 & \multirow{2}{*}{0.293} & \multirow{2}{*}{$3.7(0.32,43.5)$} \\
\hline Normal & $72(96)$ & 25 & 47 & & \\
\hline
\end{tabular}

${ }^{1}$ Fisher's test of association was used to obtain $\mathrm{P}$ values and Odds ratios. $* \mathrm{P}$ value significant at $\mathrm{P}<0.05$

\section{Discussion}

This study sought to investigate the relationship between frequency and timing of ANC visits with birth weight, birth length, head circumference, Apgar score, birth complications, delivery mode, preterm birth and duration of labour in women aged 15-49 at Hatcliffe Polyclinic, Harare. In this study increased frequency and early registration of ANC visits had a significant relationship with birth weight and length. Only for head circumference was the relationship significant for number of ANC visits. Similarly a study conducted to identify a broad range of interventions that positively affect pregnancy outcomes and reduce infant mortality found that increased frequency and proper timing of ANC visits were found to be effective in producing positive birth outcomes [18]. Other studies have come to the same conclusion that ANC visits are an instrumental factor in improving birth outcomes [19, 20].

In this study, early registration for ANC had a positive relationship with the birth weight. Our findings agree with a study from Uruguay that also showed that early registration had a positive relationship with the birth weight [21]. Likewise, having the first ANC visit during the first trimester was found to improve birth weight by 304 grams [19]. From these results, promotions to encourage mothers to register early for ANC will be useful so as to reduce the risk of LBW babies. 
From this study, there was no relationship between the number of ANC visits and the Apgar score of the newborn. in the contrary, a study by colleagues from Grand Valley State University in Michigan, USA in 1999 that examined the relationship between the number of ANC visits and infant Apgar scores found a positive relationship between ANC visits and infant Apgar scores [22]. This difference with our results could not be due to different samples sizes, were the latter assessed 90 women whilst we had a sample size of 75 women. It may be reflective of the differences in the quality of care in our low income vs. the high income setting in America. The use of the Kessner's index [23] to evaluate the adequacy of prenatal care is recommended for future studies.

Despite the different sample sizes our results are similar to the study conducted in Nigeria which examined the role of ANC on small size at birth based on the 2003 Nigeria Demographic and Health Survey data [24]. The Nigerian study found that ANC visits were associated with lesser chances of giving birth to small sized babies [24]. Although only $10.6 \%$ of children in our study had low birth weight, community awareness campaigns are recommended as strategy to prevent adverse birth outcomes in line with the World Health Assembly (WHA) target to achieve a $30 \%$ reduction in low birth weight in communities by 2025 [25].

Birth complications used in this study were delivery by $\mathrm{C}$-section, preterm birth and longer duration of labour. Our study found that ANC visits had a positive relationship with the birth outcomes but no relationship with the birth complications. This is similar to a study which concluded that ANC visits improved birth weight although they failed to reduce the possibility of preterm birth in the urban areas [10]. It can be assumed that birth complications are due to many other factors beyond ANC visits.

A study that explored parent-offspring data from the Medical Birth Registry of Norway (MBRN) to investigate the genetic and environmental influences on birth weight, birth length, head circumference, and gestational concluded that $50 \%$ of the variation in birth weight, birth length, and head circumference may be explained by genetic factors [26]. These Norwegian investigators also reported that an increase in maternal age was associated with birth complications such as prolonged labour [26].

In our study, most women received care from certified nurses and the mean duration of labour was found to be 7.6 hours. This is comparable to a study conducted in nine hospital settings in 
the USA in 1996 among women who received care from certified nurse-midwives found that the mean length of labour was 7.7 hours [27]. Our study had some limitations. It was facility based therefore only capturing women with health seeking behavior and ignoring those who may have delivered in the households. This could have had influenced the seemingly low sample size, considering that normally mothers fail to come for postnatal care services (PNC) after giving birth. Furthermore, we may have underestimated the negative birth outcomes and complications as most women are quickly referred to referral hospitals or private institutions and after delivery may continue with growth monitoring activities at the same place. Although our study was localized in an urban setting hence findings may not be representative to those in rural areas and those in urban areas who seek services in the private sector, this was a low resource area and findings may be comparable to other low resource settings and the urban poor. These findings can be used to design appropriate messages for awareness campaigns aimed at to improving ANC attendance in similar settings.

\title{
Conclusions
}

In this study increased frequency and early registration for ANC visits had a positive relationship with birth weight, birth length and head circumference. These findings show the need for improving the uptake of ANC services, early registration for ANC in the first trimester and adoption of community wide strategies to ensure that pregnant women attend all recommended visits for improved birth outcomes in this and related settings. Therefore, nutrition and health education programmes targeting all women of childbearing age are warranted.

\author{
Abbreviations \\ ANC - Antenatal care \\ CI - Confidence Interval \\ LBW - Low Birth Weight \\ LMICs - Low-and middle-income countries \\ OR -Odds Ratio \\ SD -Standard Deviation
}

\section{Declaration}

\section{Ethics approval and consent to participate}

The study was conducted in agreement with the Helsinki Declaration, and approved by the Hatcliffe Polyclinic Administrator management. Ethical approval was granted by the Medical 
Research Council of Zimbabwe (MRCZ/B/1438). Written informed consent was obtained from the study participants and for participants below 16 years old, after they had assented written informed consent was obtained from a parent or legal guardian.

\section{Consent for publication}

No previously published material has been used in this study.

\section{Availability of data and material}

The anonymised datasets used and/or analysed during the current study are available from the corresponding author on reasonable request.

Competing interests. All authors declare no competing interests.

Funding. No external funding was received.

\section{Author' contributions}

TM and SM designed the study and wrote the initial draft. PC contributed to data analysis and subsequently reviewed manuscript drafts. All authors read and approved the final manuscript.

\section{Acknowledgements}

We would like to thank the mothers from Hatcliffe area for participating in this study. Thank you to the Harare City health department and Hatcliffe clinic staff for facilitating data collection. 


\section{References}

1. Muchie KF: Quality of antenatal care services and completion of four or more antenatal care visits in Ethiopia: a finding based on a demographic and health survey. BMC pregnancy and childbirth. 2017, 17(1):300.

2. WHO: WHO recommendations on antenatal care for a positive pregnancy experience: World Health Organization (WHO); 2016. Geneva, Switzerland. https://www.who.int/reproductivehealth/news/antenatal-care/en/ Accessed: 23 Mar 2020.

3. Lincetto O, Mothebesoane-Anoh S, Gomez P, Munjanja S: Antenatal Care-World Health Organization. URL: http://www.who.int/pmnch/media/publications/aonsectionIII_2 pdf 2013. Accessed: 23 Feb 2020.

4. WHO: WHO antenatal care randomized trial: manual for the implementation of the new model. In.: World Health Organization (WHO); 2002. Geveva, Switzerland. https://apps.who.int/iris/handle/10665/42513 Accessed: 23 Mar 2019.

5. Bhutta ZA, Das JK, Rizvi A, Gaffey MF, Walker N, Horton S, Webb P, Lartey A, Black RE: Evidence-based interventions for improvement of maternal and child nutrition: what can be done and at what cost? The Lancet. 2013, 382::452-477.

6. Ruel MT, Alderman H: Nutrition-sensitive interventions and programmes: how can they help to accelerate progress in improving maternal and child nutrition? The Lancet. 2013, 382(9891):536-551.

7. $\quad$ Roman L, Raffo JE, Zhu Q, Meghea CI: A statewide Medicaid enhanced prenatal care program: impact on birth outcomes. JAMA Pediatrics. 2014, 168(3):220-227.

8. Christian P, Lee SE, Donahue Angel M, Adair LS, Arifeen SE, Ashorn P, Barros FC, Fall $\mathrm{CH}$, Fawzi WW, Hao W et al: Risk of childhood undernutrition related to small-forgestational age and preterm birth in low- and middle-income countries. Int J Epidemiol. 2013, 42(5):1340-1355.

9. Zelazny ZA: Indigent women and access to prenatal care. 2011. University of Nevada, Las Vegas (UNLV). Theses, Dissertations, Professional Papers, and Capstones. 1243. https://digitalscholarship.unlv.edu/thesesdissertations/1243 Accessed: 24 Mar 2020

10. Gajate-Garrido G: The impact of adequate prenatal care on urban birth outcomes: an analysis in a developing country context. Economic Development and Cultural Change. 2013, 62(1):95-130.

11. FNC: Zimbabwe 2018 National Nutrition Survey Report. In. Food and Nutrition Council (FNC), Hatcliffe, Harare, Zimbabwe: Food and Nutrition Council (FNC); 2018. https://www.unicef.org/zimbabwe/media/1056/file/Zimbabwe\%202018\%20National\%20Nutr ition\%20Survey\%20Report.pdf Accessed: 13 Nov 2019

12. Accortt EE, Cheadle AC, Schetter CD: Prenatal depression and adverse birth outcomes: an updated systematic review. Maternal and Child Health. 2015, 19(6):1306-1337.

13. Blencowe H, Cousens S, Jassir FB, Say L, Chou D, Mathers C, Hogan D, Shiekh S, Qureshi ZU, You D: National, regional, and worldwide estimates of stillbirth rates in 2015, with trends from 2000: a systematic analysis. The Lancet Global Health. 2016, 4(2): e98-e108. 
14. ZimStat: Zimbabwe Demographic and Health Survey (ZDHS) 2015 Report. In. Harare, Zimbabwe: Zimbabwe National Statistics Agency (ZIMSTAT); 2016.

https://dhsprogram.com/pubs/pdf/FR322/FR322.pdf Accessed: 5 Oct 2019

15. ZIMSTAT: Zimbabwe Population Census, 2012: Zimbabwe National Statistics Agency (ZIMSTAT); 2012.

http://www.zimstat.co.zw/sites/default/files/img/publications/Population/National Report.pdf

Accessed: 11 Mar 2019

16. ZIMSTAT: Zimbabwe Multiple Indicator Cluster Survey 2014, Final Report. In.: ZIMSTAT Harare; 2015. https://microdata.worldbank.org/index.php/catalog/2527 Accessed: 1 Sept 2019

17. Villar J, Ismail LC, Victora CG, Ohuma EO, Bertino E, Altman DG, Lambert A, Papageorghiou AT, Carvalho M, Jaffer YA: International standards for newborn weight, length, and head circumference by gestational age and sex: the Newborn Cross-Sectional Study of the INTERGROWTH-21st Project. The Lancet. 2014, 384(9946):857-868.

18. Bloom JK: Prenatal interventions that improve native American pregnancy outcomes and reduce infant mortality: an integrative review. 2012. Doctoral dissertation, College of Nursing, Montana State University-Bozeman, USA. https://scholarworks.montana.edu/xmlui/handle/1/937 Accessed: 21 May 2019

19. Habibov N, Fan L, Campbell D, Cheung CH: Effect of prenatal care frequency, timing, and quality on childbirth weight in Tajikistan. World Medical \& Health Policy. 2017, 9(1):89102.

20. Bersak TA: Essays on Health, Health Care Utilization, and Public Insurance. 2015. Doctoral dissertation, Clemson University, South Carolina, USA. All Dissertations. 1796. https://tigerprints.clemson.edu/all_dissertations/1796 Accessed: 21 Feb 2020

21. Todd Jewell R, Triunfo P: The impact of prenatal care on birthweight: the case of Uruguay. Health Economics. 2006, 15(11):1245-1250.

22. Pernie S: Relationship Between Number of Prenatal Visits and Infant Apgar Scores. 1999. https://scholarworks.gvsu.edu/theses/450/ Accessed: 21 Dec 2019

23. Alexander GR, Kotelchuck M: Quantifying the adequacy of prenatal care: a comparison of indices. Public Health Reports. 1996, 111(5):408.

24. Chuku SN: Low birth weight in Nigeria: Does antenatal care matter. Journal of Arts in Development Studies, Institute of Social Study Netherland 2008, 12:66-71.

25. WHO/WHA: WHA Global Nutrition Targets: Low birth weight policy brief. In: WHO \& WHA Global Nutrition Targets. Geneva, Switzerland: World Health Organisation (WHO); 2014. https://apps.who.int/iris/handle/10665/149020 Accessed: 14 Jan 2020

26. Lunde A, Melve KK, Gjessing HK, Skjærven R, Irgens LM: Genetic and environmental influences on birth weight, birth length, head circumference, and gestational age by use of population-based parent-offspring data. American journal of epidemiology. 2007, 165(7):734741.

27. Albers LL: The duration of labor in healthy women. Journal of Perinatology. 1999, 19(2):114-119. 